\title{
Dynamics of Sodium and Lithium Counter-Ions and Water Molecules in Cation-Exchange Resins as Shown by NMR Spectroscopy
}

\author{
Muneki OHuchi, Peter MEadows, ${ }^{*}$ Hiroharu Horiuchi, ${ }^{* *}$ \\ Yoshirou SAKAI, ${ }^{* * *}$ and Kazuo FuRIHATA ${ }^{* * * *}$ \\ Miura Institute of Environmental Science, Miura Co. Ltd., \\ 864-1, Tsuji, Hojo, Ehime 799-2430, Japan \\ ${ }^{*}$ JEOL (UK) Ltd., JEOL House, Silver Court, Watchmead, Welwyn Garden City, Hertfordshire, AL7 1LT, U.K. \\ ${ }^{* *}$ Advanced Instrumentation Center for Chemical Analysis, Ehime University, \\ 2-5, Bunkyo, Matsuyama, Ehime 790-8577, Japan \\ ${ }^{* * *}$ Department of Applied Chemistry, Faculty of Engineering, Ehime University, 3, Bunkyo, \\ Matsuyama, Ehime 790-8577, Japan \\ ${ }^{* * * *}$ Division of Agriculture and Agricultural Life Sciences, University of Tokyo, \\ 1-1-1, Yayoi, Bunkyo-ku, Tokyo 113-8657, Japan
}

(Received February 21, 2000; Accepted May 22, 2000)

\begin{abstract}
The dynamics of water molecules and cations (lithium and sodium counter-ions) in cation-exchange resins were investigated by measuring relaxation time and self-diffusion coefficients of ${ }^{1} \mathrm{H},{ }^{7} \mathrm{Li}$, and ${ }^{23} \mathrm{Na}$ NMR. Five geltype cation-exchange resins with different by the crosslinked poly(styrene sulfonic acid) copolymer swollen in water and salt aqueous solution were studied. A macroporous-type resin was studied for comparison. Activation energy for the lithium and sodium ions obtained from the Arrhenius plots of spin-lattice relaxation times $T_{1}$ correlated well with the crosslinking of resins. Since $T_{1}$ of the cations in every resin are shorter than in corresponding aqueous solution, the correlation time of the rotational motion of cations is longer in the resins. With higher cross-linking of the resin, the rotational motion of the cations becomes slower and more restricted. Self-diffusion coefficients of water molecules and lithium and sodium counter-ions in the gel-type resin were directly measured by pulsed field-gradient NMR methods. Translational diffusion of these species was closely related to the cross-linking of resin similar to $T_{1}$. The diffusion of water molecules and cations becomes slower in higher cross-linked resin. Apparent diffusion coefficients of $\mathrm{Li}^{+}$ions and water molecules were dependent on diffusion time. This may be explained by restricted diffusion in a three dimensional network structure of gel-heteroporous type ion-exchange resins.

KEY WORDS Cation-Exchange Resin / Dynamics / Restricted Diffusion / Pulsed Field-Gradient Nuclear Magnetic Resonance $/{ }^{7} \mathrm{Li}$ Nuclear Magnetic Resonance $/{ }^{23} \mathrm{Na}$ Nuclear Magnetic Resonance / Crosslinkage /
\end{abstract}

Ion-exchange resins are widely used for general treatment of boiler feed and process water as basic ionexchange treatment. To systematically apply ionexchange resins to ion-exchange treatment, chemical characterization of the ion-exchange resin, exchange capacity and selectivity of the ion-exchanger, rate of ionexchange and etc., are important. ${ }^{1}$ The rate of ionexchange is determined by ion transportation speed and diffusion at the ion-exchange resin. Ion transportation speed is dominated by the rate of dissociation, particle diffusion of the counter-ion within the ion-exchanger, and film diffusion in the borders within the beads and through layers. This means inter-diffusion of counterions in adherent films. ${ }^{1}$ The slowest rate of ion-exchange is dominated by ion transportation speed. ${ }^{1}$ Film diffusion, that concentration differences across the film are instantly averaged out, is generally so much faster than particle diffusion. Within the ion-exchange resin of crosslinked poly(styrene sulfonic acid) copolymer, particle diffusion speed is slowest and limited by ion transportation speed. To determine this particle diffusion speed, it is necessary to measure the diffusion coefficient of dissociated counter-ions within the ion-exchange resin. This may be done indirectly using chemical or isotopic profiles of a breakthrough curve and/or a tracer using an isotope or radioisotope as a probe ${ }^{2}$ and may take several hours. However, by these methods, it is difficult to separate between particle diffusion within a resin and film diffusion, and thus difficult to analyze transportation of ions. However, the diffusion coefficient of mobile water molecules within the ion-exchange resin was measured directly by pulsed field-gradient nuclear magnetic resonance (PFG-NMR) spectroscopy. ${ }^{3}$ PFG-NMR is attracting attention as a probe of microscopic, but volumetrically averaged, properties of materials. PFG-NMR is ideal for measuring time-dependent diffusion coefficients. ${ }^{4}$ The measurement is nondestructive and does not involve the introduction of chemicals or isotopic tracers. Recently, using PFG-NMR, we measured diffusion coefficients of dissociated $\mathrm{Na}^{+}$and $\mathrm{Li}^{+}$counter-ions within ion-exchange resin. ${ }^{5}$

As ion-exchange resins and membranes, there are geltypes and macroporous-types. ${ }^{1}$ The phase of gel-type ionexchange resin is homogeneous, and such a structure is termed "crosslinked gel-heteroporous". A three-dimensional network structure within this type of copolymer with nearly normal distribution has micropores. In ionexchange resins of the macroporous-type, holes are 20 to $100 \mathrm{~nm}$ in diameter. The size of the network structure of gel-type resins is controlled by the amount of crosslinkage agent. The size of the three-dimensional network structure becomes smaller as the amount of crosslinked agent increases. The size of this network structure influences the sieving effect of ions and rotational motion of 
counter-ions. The dynamics of dissociated counter-ions within gel-type ion-exchange resins are very important for analysis of transportation within the ion-exchange resin.

By investigating the motion of dissociated counterions within the ion-exchange resin, it is possible to understand ion transportation. It is very important to know the correlation time of rotational motion of counter-ions within ion-exchange resins of different crosslinkage obtained by relaxation time measurements by NMR. The motion of $\mathrm{Li}^{+}$and $\mathrm{Na}^{+}$counter-ions was investigated by NMR relaxation methods. The relaxation times of $\mathrm{Na}^{+}$and $\mathrm{Li}^{+}$ions within gel-type ionexchange resins of crosslinked poly(styrene sulfonic acid) copolymer swollen with water were measured by NMR methods. A macroporous-type resin was also studied for comparison.

To study the diffusion coefficients of counter-ions within ion-exchange resins, it is important to know particle diffusion. Studies on diffusion of water molecules within ion-exchange resin using the PFG-NMR method have been reported. ${ }^{3,5}$ Within the network structure of ion-exchange resins, mobile water molecules and dissociated $\mathrm{Na}^{+}$and $\mathrm{Li}^{+}$ions within the ion-exchange resin do not diffuse freely. Thus it is difficult to obtain selfdiffusion coefficients. To study restricted diffusion, diffusion coefficients were measured by general PFG stimulated echo NMR method (PFG-STE). ${ }^{4,6}$ However, with long diffusion times, apparent diffusion coefficients were influenced by magnetic field inhomogeneity of the sample and exact diffusion coefficient measurement was impossible. ${ }^{7}$ Therefore, to completely remove the influence of an inhomogeneous magnetic field, the PFG-STE pulse sequence was modified. Even using this modified PFGSTE method, apparent diffusion coefficients of ${ }^{1} \mathrm{H}$ and ${ }^{7} \mathrm{Li}$ nuclei were dependent on diffusion time. This is called "restricted diffusion". However, with ${ }^{23} \mathrm{Na}$, because relaxation time was short, measurement of the timedependent diffusion coefficient was impossible due to short ${ }^{23} \mathrm{Na}$ echo decays. Diffusion coefficients of $\mathrm{Li}^{+}$and $\mathrm{Na}^{+}$counter-ions and mobile water molecules within various ion-exchange resins were investigated with respect to crosslinkage.

\section{MATERIAL AND METHOD}

\section{Materials}

Samples of DOWEX 50W-X2, 50W-X4, 50W-X8, and $50 \mathrm{~W}-\mathrm{X} 12$ from Dow Chemical Co. are cation-exchange resins of gel-type crosslinked poly(styrene sulfonic acid) copolymer with a dry bead size of 150 to $300 \mu \mathrm{m}$ in diameter, with total ion-exchange capacity of $5.2,5.2,5.1$, and $5.0 \mathrm{Meq} / \mathrm{dry}-\mathrm{g}$, and with a water content of $80 \%$, $68 \%, 53 \%$, and $45 \%$, respectively. ${ }^{8}$ The degree of crosslinking of DOWEX 50W-X2, 50W-X4, 50W-X8, and 50W$\mathrm{X} 12$ is $2 \%, 4 \%, 8 \%$, and $12 \%$, respectively. Dry bead size was taken as that before the introduction of an ionexchange functional group. The degree of crosslinkage is divinylbenzene crosslinker content in wt\% of the reaction mixture. DOWEX HCR-W2 and MSC-1 cationexchange resin of crosslinked poly(styrene sulfonic acid) have dry bead size of 300 to $840 \mu \mathrm{m}$, and crosslinkage of $8 \%$. MSC-1 is a macroporous-type of the same copolymer

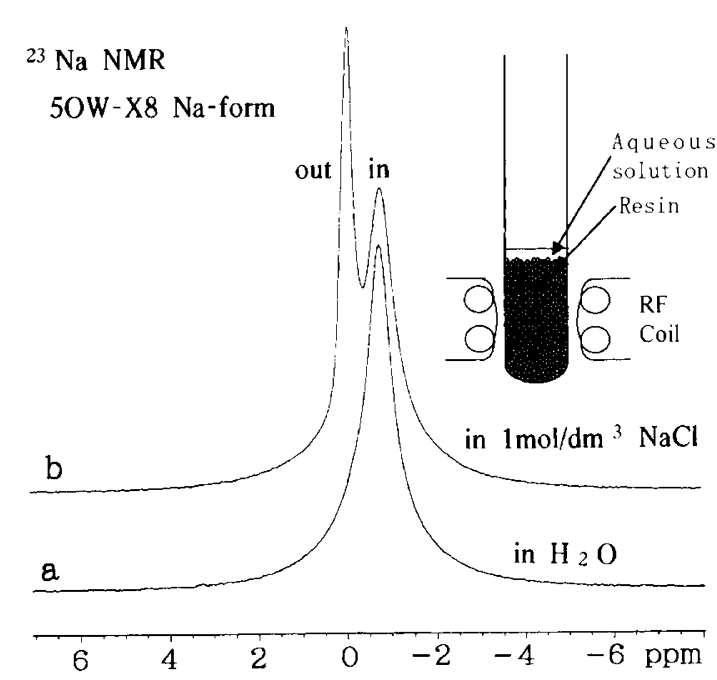

Figure 1. ${ }^{23} \mathrm{Na} \mathrm{NMR}$ spectra of ion-exchange resin in aqueous solution. Spectrum a is that of the resin filled with water, and spectrum $b$ that of the resin filled with $1 \mathrm{M}-\mathrm{NaCl}$ aqueous solution. Signals $a$ and $b$ are not normalized. Upper right; cation-exchange resins of crosslinked poly(styrene sulfonic acid) copolymer swollen with aqueous solutions in $5 \mathrm{~mm} \phi \mathrm{OD} \mathrm{NMR}$ tube. Acquisition parameters were $5 \mathrm{kHz}$ for spectral width and $18 \mu \mathrm{s}$ for $90^{\circ}$ pulse length.

and others are gel-type. The samples of chemical grade resin are converted to the sodium form by swelling in $10 \% \mathrm{NaCl}$ aqueous solution, or to the lithium form using $10 \% \mathrm{LiCl}$ aqueous solution. The resins were washed by water and used for measurement. ${ }^{5}$ The water used was distilled. Ion-exchange resin either as sodium form or lithium form was placed into a $5 \mathrm{~mm} \phi \mathrm{OD} \mathrm{NMR}$ tube and filled with water or the corresponding aqueous solution as in Figure 1.

\section{Experimental Method}

NMR Spectra of Gel-Type Cation-Exchange Resin. The sample swollen with water, the ${ }^{23} \mathrm{Na}$ NMR spectrum of the Na-form and ${ }^{7} \mathrm{Li} \mathrm{NMR}$ spectrum of the Li-form, consisted of only a single peak as in Figure 1a. However, when the NMR spectra of ${ }^{23} \mathrm{Na}$ in $\mathrm{NaCl}$ aqueous solution, ${ }^{7} \mathrm{Li}$ in $\mathrm{LiCl}$ aqueous solution, and ${ }^{1} \mathrm{H}$ in water and aqueous solutions were measured, two peaks were observed as in Figure 1b. The peaks in each spectrum were assigned as inside and outside ion-exchange resins. ${ }^{5}$ The higher field ${ }^{23} \mathrm{Na}$ signal for the samples containing $1 \mathrm{M}$ $\mathrm{NaCl}$ aqueous solution in Figure 1a agrees the ${ }^{23} \mathrm{Na}$ chemical shift of the sample swollen with water. Also it relaxes faster than the lower field signals in ${ }^{23} \mathrm{Na}$ resonance. Therefore the higher field signal can be assigned to the sodium within the resin, and also ${ }^{7} \mathrm{Li}$ signal is same matter. Relaxation time and diffusion coefficient were measured for the single peak of the ${ }^{23} \mathrm{Na}$ and ${ }^{7} \mathrm{Li}$ spectra within resin swollen in water, and the higher field peak of the ${ }^{23} \mathrm{Na}$ and ${ }^{7} \mathrm{Li}$ spectra within resin swollen in the corresponding aqueous solution and the ${ }^{1} \mathrm{H}$ spectrum in water arising from within the ion-exchange resin at $30 \pm 0.5^{\circ} \mathrm{C}$. Temperature was controlled with a suitable temperature controller.

Measurement of Relaxation Times. Relaxation times of $\mathrm{Na}^{+}$and $\mathrm{Li}^{+}$counter-ions within the resins were measured in a $5 \mathrm{~mm} \phi$ OD tube using a JEOL $270 \mathrm{MHz}$ NMR 
a. Pulsed Field-gradient Hahn Spin-echo

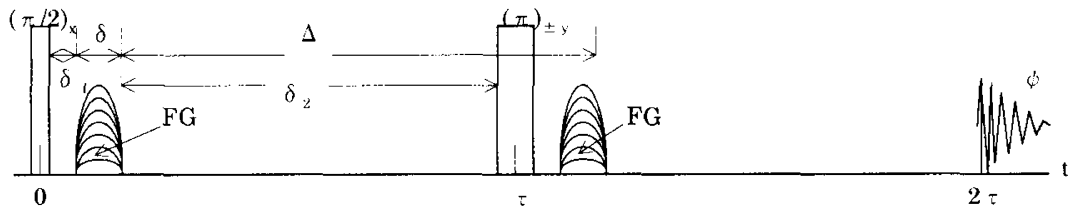

b. PFG-stimulated echo (PFG-STE)

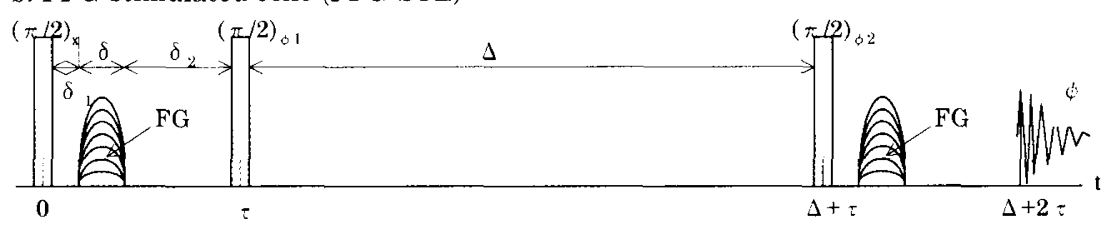

c. Modified PFG-STE

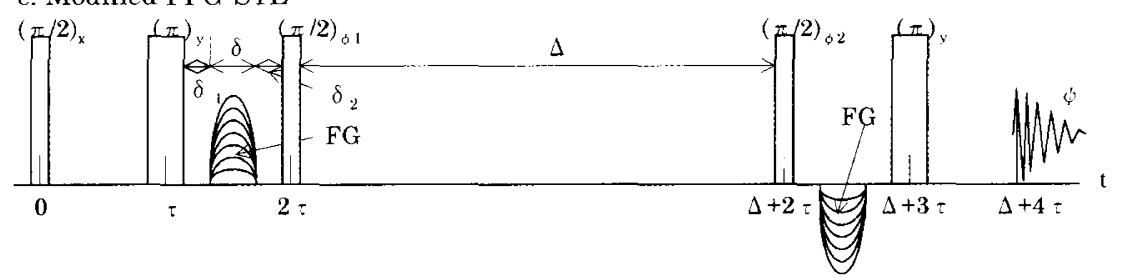

Figure 2. Pulse sequences for measuring diffusion coefficients of dissociated $\mathrm{Na}^{+}$and $\mathrm{Li}^{+}$counter-ions and water molecules within resin. Pulse sequence (a) is by pulsed field-gradient Hahn spin-echo method (PFG-SE), (b) PFG-stimulated echo method (PFG-STE) and (c) modified PFG-STE, using half-sine shaped FG-pulse. See text.

instrument equipped with a multi-nuclear NMR system in a $10 \mathrm{~mm} \phi$ OD NMR probe. NMR frequency of ${ }^{7} \mathrm{Li}$ and ${ }^{23} \mathrm{Na}$ was $105.00 \mathrm{MHz}$ and $71.46 \mathrm{MHz}$, respectively. Spin-lattice relaxation time $T_{1}$ was measured using the spin inversion recovery method of $180^{\circ}-\tau-90^{\circ}-\mathrm{FID}^{9}$. Spin-spin relaxation time $\left(T_{2}\right)_{\mathrm{SE}}$ was measured using the Hahn spin-echo(SE) method of $90^{\circ}{ }_{x}-\tau-180^{\circ}{ }_{y}-\tau$-echo. ${ }^{9}$ Spin-spin relaxation time $\left(T_{2}\right)_{\mathrm{CP}}$ was measured using the Carr-Purcell Meiboom Gill (CPMG) method of $90^{\circ}{ }_{x}^{-}$ $\left(\tau_{\mathrm{CP}}-180^{\circ}{ }_{y}-\tau_{\mathrm{CP}}\right)_{n}-$ echo. $^{9}$ Spin-lattice relaxation time in the rotating frame $\left(T_{1}\right)_{\rho}$ was measured using the spin locking method of $90^{\circ}{ }_{x} \mathrm{SL}_{y}(\tau)$-FID. ${ }^{10,11}$ The $180^{\circ}$ pulse used a composite pulse of $90^{\circ} 180^{\circ} 90^{\circ}$ to eliminate pulse inaccuracy. Acquisition parameters were $5 \mathrm{kHz}$ for spectral width of ${ }^{23} \mathrm{Na}$ and $2 \mathrm{kHz}$ for ${ }^{7} \mathrm{Li}$, and $18 \mu$ s for $90^{\circ}$ pulse length of ${ }^{23} \mathrm{Na}$ and $15 \mu \mathrm{s}$ for ${ }^{7} \mathrm{Li}$, respectively. Measurement of $T_{1}$ and $\left(T_{2}\right)_{\mathrm{SE}}$ was made by varying the pulse interval time $\tau$; measurement of $\left(T_{2}\right)_{\mathrm{CP}}$ was done by fixing $\tau_{\mathrm{CP}}$ at $1,3,5,10 \mathrm{~ms}$ and varying " $n$ ". In measurement of $\left(T_{1}\right)_{\rho}$, spin locking magnetic field strength $\mathrm{SL}_{y}$, that is, $\omega_{1}$ was set at 0.1 to $2.5 \mathrm{mT}$ with varying " $\tau$ ". Although $\mathrm{Na}^{+}$and $\mathrm{Li}^{+}$ions and water molecules within the ion-exchange resin swollen with water exist to various chemical states ${ }^{12}$, relaxation curve was shown to be a single decay. Since this indicated only a single chemical species, relaxation time was calculated from the slope of relaxation curve of the NMR signal for dissociated counter-ions and mobile water molecules. Error in measurement of relaxation time was approximately $5 \%$.

Measurement of Diffusion Coefficients. Diffusion coefficients were measured using a JEOL $500 \mathrm{MHz}$ NMR instrument equipped with a multi-nuclear system of $5 \mathrm{~mm} \phi$ OD NMR probe, and shaped pulsed field-gradient unit with an actively shielded gradient coil. Resonance frequencies of ${ }^{1} \mathrm{H},{ }^{7} \mathrm{Li}$, and ${ }^{23} \mathrm{Na}$ were $500.16 \mathrm{MHz}$, 194.48 $\mathrm{MHz}$, and $132.30 \mathrm{MHz}$, respectively. The PFG echo method (PFG-STE) was modified to remove the effects of magnetic field inhomogeneity. Diffusion coefficients of dissociated $\mathrm{Na}^{+}$and $\mathrm{Li}^{+}$ions and mobile water molecules within the resin were measured with pulsed field-gradient Hahn spin-echo method (PFG-SE), ${ }^{13}$ PFGSTE, ${ }^{14}$ and modified PFG-STE, ${ }^{7}$ as shown in Figure 2. After $(\pi / 2)_{x} \mathrm{RF}$ pulse at $t=0$ in Figure $2 \mathrm{~b}$, a second $(\pi / 2)$ pulse is applied at the end of a preparation interval, $t=$ $\tau$. This second pulse is indicated by $(\pi / 2)_{\phi 1}$ with $\phi_{1}= \pm x$ or $\pm y$ in the rotating frame of reference. ${ }^{15}$ At the end of the store interval, at time $t_{\mathrm{b}}=(\tau+\Delta)$, the third $(\pi / 2)$ pulse is applied as $(\pi / 2)_{\phi 2}$ with $\phi_{2}= \pm x$ or $\pm y$. Finally after a read interval, the echo occurs at time $t_{\mathrm{c}}$ where usually the sequence requires that $\left(t_{\mathrm{c}}-t_{\mathrm{b}}\right)=\tau$. For all sequences in Figure 2, length $\delta$ is the width of an applied gradient pulse applied between RF pulses, or between an RF pulse and echo. The time interval from the RF pulse to the start of the gradient pulse is $\delta_{1}$, and $\delta_{2}$ is the time interval from the end of the gradient pulse to the next RF pulse or echo. $\delta_{1}, \delta_{2}$, and $\delta$ apply to all gradient pulses in the sequence and the spin storage time $\Delta$ is shown in Figure 2.

As the diffusion coefficient of $\mathrm{H}_{2} \mathrm{O}$ and $\mathrm{Na}^{+}$ion in $1 \mathrm{M}$ $\mathrm{NaCl}$ aqueous solution at $25^{\circ} \mathrm{C}$ is already known, ${ }^{16,17}$ the strength of the pulsed field gradient was corrected from the self-diffusion coefficient of water molecules and $\mathrm{Na}^{+}$ ions by the PFG-SE method at $\tau=10 \mathrm{~ms}$. At each magnetic field gradient, agreement with gradient was within $5 \%$. The apparent diffusion coefficient is measured by pulse sequence in Figure 2 where the gradient magneticfield strength is varied from 0 to $1.2 \mathrm{~T} \mathrm{~m}^{-1}$ and fieldgradient pulse times $\delta$ were selected at $1,1.5$, and $2 \mathrm{~ms}$ for ${ }^{1} \mathrm{H}$ NMR, at 2,3 , and $6 \mathrm{~ms}$ for ${ }^{7} \mathrm{Li} \mathrm{NMR}$, and at 5 to 9 $\mathrm{ms}$ for ${ }^{23} \mathrm{Na} \mathrm{NMR}$. And times $\Delta$ were measured at $10 \mathrm{~ms}$ to $2 \mathrm{~s}$ for ${ }^{1} \mathrm{H} \mathrm{NMR}$, at $20 \mathrm{~ms}$ to $4 \mathrm{~s}$ for ${ }^{7} \mathrm{Li} \mathrm{NMR}$, and at $3 \mathrm{~ms}$ to $25 \mathrm{~ms}$ for ${ }^{23} \mathrm{Na} \mathrm{NMR}$, respectively. Acquisition 
parameters were $5 \mathrm{kHz}$ for spectral width of ${ }^{23} \mathrm{Na}$ and $2 \mathrm{kHz}$ for ${ }^{7} \mathrm{Li}$ and ${ }^{1} \mathrm{H}$, and $16 \mu$ s for $90^{\circ}$ pulse length of ${ }^{23} \mathrm{Na}, 14 \mu \mathrm{s}$ for ${ }^{7} \mathrm{Li}$ and $9 \mu \mathrm{s}$ for ${ }^{1} \mathrm{H}$, respectively.

By the PFG-SE method ${ }^{13}$ with pulsed field-gradient of half-sine shape ${ }^{18}$ in Figure $2 \mathrm{a}$, the echo attenuation is represented by

$$
\begin{gathered}
\ln \{A(g) / A(0)\}=-\gamma^{2} D\left\{(2 / \pi)^{2} \delta^{2}(\Delta-\delta / 4) g^{2}+(2 / \pi) \delta\left(\tau^{2}+\right.\right. \\
\\
\left.\left.\tau \delta-2 \delta^{2} / 3\right) g g_{0}+2 \tau^{3} g_{0}{ }^{2} / 3\right\}
\end{gathered}
$$

where $A(g)$ and $A(0)$ are the respective echo amplitudes in the absence and presence of a gradient pulse of length $\delta, \gamma$ is the nuclear magnetic ratio, $g_{0}$ is strength of a finite steady gradient or a constant background gradient, i.e., inhomogeneity of the sample, $g$ is strength of a superimposed field-gradient pulse, $\tau$ is time delay between the RF pulses as well as between the gradient pulses, $D$ is apparent diffusion coefficient, and $\Delta$ in Fugure $2 \mathrm{a}$ is dependant only on $\tau$.

By the PFG-STE method ${ }^{14}$ with pulsed field-gradient of half-sine shape in Figure 2b, the echo attenuation is

$$
\begin{aligned}
\ln \{A(g) / A(0)\}= & -\gamma^{2} D\left\{(2 / \pi)^{2} \delta^{2}(\Delta+\tau-\delta / 4) g^{2}+(2 / \pi) \delta(2\right. \\
& \left.\tau \Delta+2 \tau^{2}-2 \delta^{2} / 3-\delta\left(\delta_{1}+\delta_{2}\right)+\left(\delta_{1}+\delta_{2}\right)^{2}\right) \\
& \left.g g_{0}+\tau^{2}(\Delta+2 \tau / 3) g_{0}{ }^{2}\right\}
\end{aligned}
$$

By the modified PFG-STE ${ }^{7}$ method with pulsed fieldgradient of half-sine shape in Figure 2c, at the time of $\delta_{1}$ $=\delta_{2}$, the echo attenuation is

$\ln \{A(g) / A(0)\}=-\gamma^{2} D\left\{(2 / \pi)^{2} \delta^{2}(\Delta+\tau-\delta / 4) g^{2}+4 \tau^{3} g_{0}{ }^{2} / 3\right\}$

With homogeneous liquid systems in high resolution NMR, because inhomogeneity of the static magnetic field is $g \gg g_{0}$ and less than $0.01 \mathrm{mT} \mathrm{m}^{-1}$, the last term of the right hand side of eq 1 to 3 can be neglected. As only the first term of eq 3 remains with the modified PFGSTE method, this method is not influenced by inhomogeneity of the magnetic field. The second term of the right hand side of eq 1 and 2 still remain with the PFG-SE and PFG-STE methods, and those methods are greatly influenced by magnetic field inhomogeneity when time $\Delta$ and/or $\tau$ are long. In this case, both water molecules and $\mathrm{Na}^{+}$and $\mathrm{Li}^{+}$ions within the ion-exchange resin are in "an inhomogeneous medium" for NMR and increase the magnetic field inhomogeneity of the sample. Therefore, in the remaining the second term of the right hand side of eq 1 and 2 with the PFG-SE and PFG-STE methods, we cannot neglect magnetic field inhomogeneity.

The apparent diffusion coefficients of water molecules within Na-formed 50W-X8 swollen in water are plotted versus the diffusion time $t$ in Figure 3, where they decrease different by the pulse sequences shown in Figure 2 as the diffusion time increases. With PFG-SE and PFG-STE methods, apparent diffusion coefficients of the water molecules decrease with diffusion time $t$. The apparent diffusion coefficient by the modified PFG-STE method is almost constant at long diffusion time, more than several $10 \mathrm{~ms}$ as in Figure 3. The modified PFGSTE method removed the influence of magnetic field inhomogeneity. Measured diffusion coefficients by PFG-SE and PFG-STE methods are less than by the modified

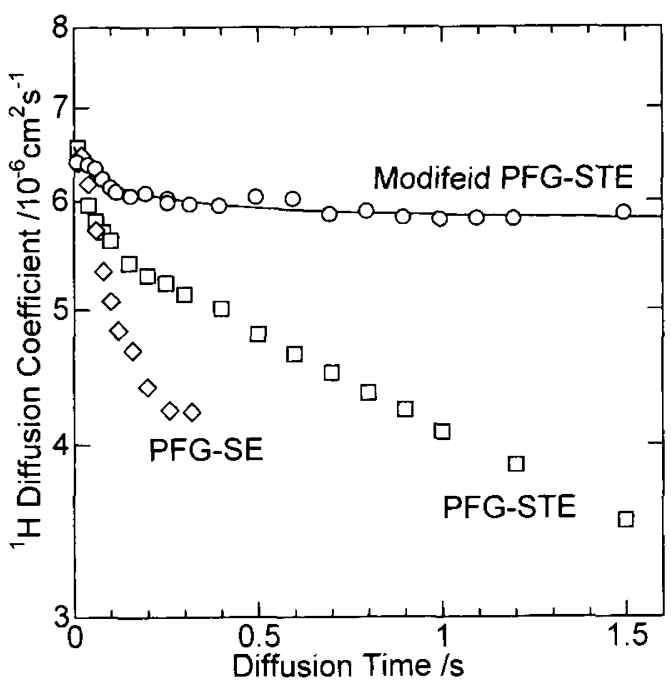

Figure 3. Diffusion time dependence of apparent diffusion coefficient for mobile water protons within $\mathrm{Na}$-formed ion-exchange resin $50 \mathrm{~W}-\mathrm{X} 8$ by the pulsed field-gradient NMR method at $30^{\circ} \mathrm{C}$. Symbol $\diamond$ is obtained by PFG-SE, $\square$ by PFG-STE, and $\bigcirc$ by modified PFG-STE. Strength of superimposed field-gradient pulse "g" was varied from 0 to $1.2 \mathrm{~T} \mathrm{~m}^{11}$ and $\Delta$ was set at $10 \mathrm{~ms}$ to $1.5 \mathrm{~s} . \delta=$ $1 \mathrm{~ms}$ and $\delta_{1}=1.05 \mathrm{~ms}$ were used. $\delta_{2}=1.05 \mathrm{~ms}$ and $\tau=3.1 \mathrm{~ms}$ with modified PFG-STE, and $\delta_{2}=4.05 \mathrm{~ms}$ and $\tau=6.1 \mathrm{~ms}$ with PFG-STE were used. Acquisition parameters were $2 \mathrm{kHz}$ for spectral width and $9 \mu \mathrm{s}$ for $90^{\circ}$ pulse length. Solid line was fitted using a leastsquares method by eq 8 .

PFG-STE method. In inhomogeneous systems such as water molecules and counter-ions within the ionexchange resin, it is better that the diffusion coefficient at diffusion time longer than a few ms may be measured by the modified PFG-STE method.

Echo attenuation $\ln \{A(g) / A(0)\}$ for each of the water molecules and $\mathrm{Na}^{+}$and $\mathrm{Li}^{+}$counter-ions within the resin is plotted as a function of gradient amplitude squared, $(2 / \pi)^{2} \gamma^{2} g^{2} \delta^{2}(\Delta+\tau-\delta / 4)$. The curves show a linear relationship except for water molecules within $50 \mathrm{~W}-\mathrm{X} 12$ resin at diffusion time $t$ greater than $300 \mathrm{~ms}$, as shown in Figures 4 and 5. Apparent diffusion coefficients within the ion-exchange resin were obtained by eq 3 using a least-squares method. Experimental error for the diffusion coefficients was approximately $10 \%$. For protons within $50 \mathrm{~W}-\mathrm{X} 12$ resin at a diffusion time greater than $300 \mathrm{~ms}$ in Figure 4, the relationship of echo attenuation $\ln \{A(g) / A(0)\}$ is nonlinear with gradient amplitude squared, $(2 / \pi)^{2} \gamma^{2} g^{2} \delta^{2}(\Delta+\tau-\delta / 4)$. Water molecules within $50 \mathrm{~W}-\mathrm{X} 12$ resin are obviously diffusion restricted. The diffusion coefficient of water molecules within $50 \mathrm{~W}$ $\mathrm{X} 12$ resin was obtained from the linear part of the slope of echo attenuation $v s$. gradient amplitude.

\section{RESULT}

Spin-Lattice Relaxation Time $T_{1}$ and Spin-Spin Relaxation Time $\mathrm{T}_{2}$

As shown in Table I, spin-lattice relaxation time $T_{1}$ of $\mathrm{Na}^{+}$counter-ions in gel-type ion-exchange resins was shorter than for $\mathrm{Na}^{+}$ions in $\mathrm{NaCl}$ aqueous solution as measured by $71.46 \mathrm{MHz} \mathrm{NMR}$ at $30^{\circ} \mathrm{C}$. Relaxation time $T_{1}$ of $\mathrm{Li}^{+}$counter-ions is shorter than $\mathrm{Li}^{+}$ions in $\mathrm{LiCl}$ aqueous solution. That is, rotational motion of those 


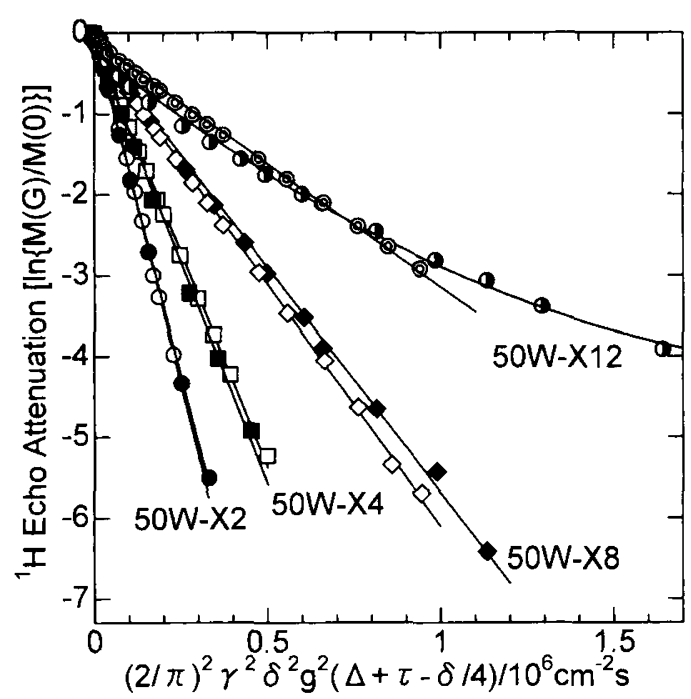

Figure 4. Effects of pulsed field-gradient on ${ }^{1} \mathrm{H}$ echo attenuation observed within Na-formed ion exchange resin $50 \mathrm{~W}-\mathrm{X} 2,50 \mathrm{~W}-\mathrm{X} 4$, $50 \mathrm{~W}-\mathrm{X} 8$, and $50 \mathrm{~W}-\mathrm{X} 12$ in water by modified PFG-STE at $30^{\circ} \mathrm{C}$. Diffusion time of opened symbols is at $200 \mathrm{~ms}$, and of closed symbols is at $700 \mathrm{~ms}$. Symbol $\bigcirc$ is within $50 \mathrm{~W}-\mathrm{X} 2, \square$ in $50 \mathrm{~W}-\mathrm{X} 4, \diamond$ in $50 \mathrm{~W}-\mathrm{X} 8$, and () in 50W-X12. $\delta$ is $1 \mathrm{~ms}, \tau=3.1 \mathrm{~ms}$ and $\mathrm{g}$ is varied from 0 to $1.2 \mathrm{~T} \mathrm{~m}^{-1}$. Acquisition parameters were $2 \mathrm{kHz}$ for spectral width and $9 \mu \mathrm{s}$ for $90^{\circ}$ pulse length. Solid line was fitted using a least-squares method by eq 3 except $50 \mathrm{~W}-\mathrm{X} 12$ at $\Delta=700 \mathrm{~ms}$.

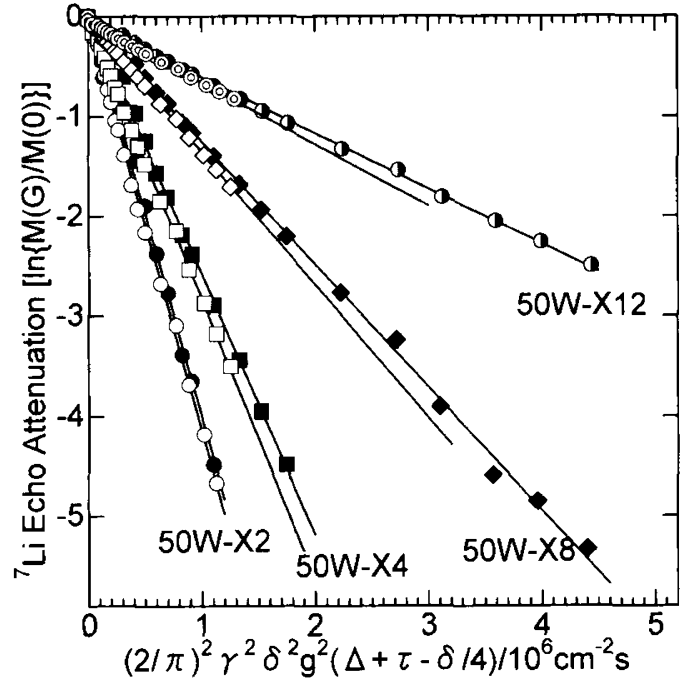

Figure 5. Effects of pulsed field-gradient on ${ }^{7} \mathrm{Li}$ echo attenuation observed within ion exchange resin $50 \mathrm{~W}-\mathrm{X} 2,50 \mathrm{~W}-\mathrm{X} 4,50 \mathrm{~W}-\mathrm{X} 8$, and $50 \mathrm{~W}-\mathrm{X} 12$ in water by modified PFG-STE at $30^{\circ} \mathrm{C}$. Diffusion time of opened symbols is at $200 \mathrm{~ms}$, and of closed symbols is at $700 \mathrm{~ms}$. Symbol $\bigcirc$ is within 50W-X2, $\square$ in 50W-X4, $\diamond$ in 50W-X8, and $\odot$ in $50 \mathrm{~W}-\mathrm{X} 12 . \delta$ is $3 \mathrm{~ms}, \tau=5.1 \mathrm{~ms}$ and $g$ is varied from 0 to $1.2 \mathrm{~T}$ $\mathrm{m}^{-1}$. Acquisition parameters were $2 \mathrm{kHz}$ for spectral width and 14 $\mu \mathrm{s}$ for $90^{\circ}$ pulse length. Solid line was fitted using a least-squares method by eq 3 .

Table I. Spin-lattice relaxation times $T_{1}(\mathrm{~s})$ and spin-spin relaxation time $T_{2}(\mathrm{~s})$ of ${ }^{23} \mathrm{Na}$ and ${ }^{7} \mathrm{Li}$ NMR within different crosslinkage ${ }^{\mathrm{a}}$ of ionexchange resin in water at $30^{\circ} \mathrm{C}$, and activation energy $\Delta E\left(\mathrm{~kJ} \mathrm{~mol}^{-1}\right)$ obtained from Arrhenius plots of relaxation time

\begin{tabular}{|c|c|c|c|c|c|c|c|c|c|c|}
\hline & \multirow{2}{*}{$\begin{array}{l}\text { Cross- } \\
\text { linkage }\end{array}$} & \multicolumn{4}{|c|}{${ }^{23} \mathrm{Na} \mathrm{NMR}$} & \multicolumn{5}{|c|}{${ }^{7} \mathrm{Li}$ NMR } \\
\hline & & $T_{1} \times 10^{3}$ & $\Delta E$ & $\left(T_{2}\right)_{\mathrm{SE}} \times 10^{3}$ & $\Delta E$ & $T_{1}$ & $\Delta E$ & $\left(T_{2}\right)_{\mathrm{SE}}$ & $\left(T_{2}\right)_{\mathrm{CP}}$ & $\Delta E$ \\
\hline $50 \mathrm{~W}-\mathrm{X} 2$ & $2 \%$ & $24.6 \pm 1.2$ & $12.6 \pm 1.3$ & $20.9 \pm 2.1$ & $9.45 \pm 0.9$ & $8.91 \pm 0.45$ & $16.2 \pm 1.6$ & $0.451 \pm 0.045$ & $8.04 \pm 0.40$ & $6.91 \pm 0.69^{b}$ \\
\hline $50 \mathrm{~W}-\mathrm{X} 4$ & $4 \%$ & $14.9 \pm 0.75$ & $13.9 \pm 1.4$ & $12.0 \pm 1.2$ & $16.0 \pm 1.6$ & $5.99 \pm 0.30$ & $15.4 \pm 1.5$ & $0.403 \pm 0.040$ & $3.97 \pm 0.20$ & $11.9 \pm 1.2^{\mathrm{b}}$ \\
\hline $50 \mathrm{~W}-\mathrm{X} 8$ & $8 \%$ & $5.19 \pm 0.26$ & $14.4 \pm 1.4$ & $3.71 \pm 0.37$ & $11.7 \pm 1.2$ & $2.78 \pm 0.14$ & $14.6 \pm 1.5$ & $0.314 \pm 0.031$ & $0.819 \pm 0.041$ & $19.4 \pm 1.9^{\mathrm{b}}$ \\
\hline $50 \mathrm{~W}-\mathrm{X} 12$ & $12 \%$ & $2.18 \pm 0.51$ & $12.7 \pm 1.3$ & $1.94 \pm 0.19$ & $10.2 \pm 1.0$ & $1.40 \pm 0.07$ & $12.0 \pm 1.2$ & $0.252 \pm 0.025$ & $0.335 \pm 0.017$ & $15.3 \pm 1.5^{\mathrm{b}}$ \\
\hline HCR-W2 & $8 \%$ & $4.33 \pm 0.22$ & $9.97 \pm 1.0$ & $3.73 \pm 0.37$ & $10.1 \pm 1.0$ & $2.52 \pm 0.13$ & $13.8 \pm 1.4$ & $0.472 \pm 0.047$ & $0.594 \pm 0.030$ & $22.4 \pm 2.2^{b}$ \\
\hline MSC-1 & $8 \%$ & $1.06 \pm 0.05$ & - & & & $0.346 \pm 0.04$ & - & $0.0104 \pm 0.01$ & $0.011 \pm 0.001^{\mathrm{d}}$ & $30.4 \pm 3.0^{\mathrm{C}}$ \\
\hline $0.1 \mathrm{M} \mathrm{NaCl}$ & & $65.8 \pm 3.3$ & $9.7 \pm 1.0$ & $58.8 \pm 5.9$ & $6.9 \pm 0.7$ & & & & & \\
\hline $1 \mathrm{M} \mathrm{LiCl}$ & & & & & & $18.4 \pm 0.92$ & $11.2 \pm 1.1$ & & & \\
\hline
\end{tabular}

${ }^{\mathrm{a}}$ Divinylbenzene/(styrene+divinylbenzene). ${ }^{\mathrm{b}}$ From $\left(T_{2}\right)_{\mathrm{CP}} \cdot{ }^{\mathrm{c}}$ From $\left(T_{2}\right)_{\mathrm{SE}} \cdot{ }^{\mathrm{d}}\left(T_{1}\right)_{\rho}$.

$\mathrm{Na}^{+}$and $\mathrm{Li}^{+}$ions within the resin is slower than in corresponding aqueous solution because of restriction within the three-dimensional structure of crosslinked ion-exchange resin. These ions relaxed faster within the resin than at greater crosslinking in gel-type resins.

Relaxation time $\left(T_{2}\right)_{\mathrm{SE}}$ of ${ }^{23} \mathrm{Na}$ within the gel-type ionexchange resin was almost equal to $T_{1}$, as shown in Table I. Relaxation time $\left(T_{2}\right)_{\mathrm{SE}}$ of ${ }^{7} \mathrm{Li}$ within the resin was quite different to $T_{1}$. Thus the influence of the magnetic field inhomogeneity and existence of chemical exchange are significant.

Relaxation times $T_{1}$ and $T_{2}$ of $\mathrm{Na}^{+}$and $\mathrm{Li}^{+}$counterions within gel-type ion-exchange resins were measured at different temperatures. $T_{1}$ and $\left(T_{2}\right)_{\mathrm{SE}}$ of ${ }^{23} \mathrm{Na}$, and $T_{1}$ and $\left(T_{2}\right)_{\mathrm{CP}}$ of ${ }^{7} \mathrm{Li}$ were nearly linear against the reciprocal of temperature as shown in Figures 6 and 7, and activation energy $\Delta E$ of molecular and ionic motion may be obtained from the Arrhenius plot of $\ln \left(T_{1}\right) \propto-(\Delta E / R T)^{5}$ as shown in Table I. Activation energy $\Delta E$ of motion of the $\mathrm{Na}^{+}$and $\mathrm{Li}^{+}$ions within the resin was larger than those of motion of ions in corresponding aqueous solution. As shown in Table I, activation energy of rotational motion of the $\mathrm{Na}^{+}$counter-ions within resins showed similar values at 13 to $14 \mathrm{~kJ} \mathrm{~mol}^{-1}$. Activation energy of rotational motion of $\mathrm{Li}^{+}$counter-ions within resins with different crosslinkage, showed different values at 12 to $16 \mathrm{~kJ} \mathrm{~mol}^{-1}$ and decreased as crosslinkage increased. Relaxation times $\left(T_{2}\right)_{\mathrm{SE}}$ of ${ }^{7} \mathrm{Li}$ by the $\mathrm{SE}$ method was almost constant against reciprocal of temperature(only 50W-X8 is shown in Figure 9).

Relaxation times of a macroporous-type resin MSC-1 were compared with those of two gel-type resins of the small bead size $50 \mathrm{~W}-\mathrm{X} 8$ and the same bead size HCR-W2 with the same crosslinkage. In Figures 8 and 9, relaxation time $T_{1}$ of $\mathrm{Na}^{+}$and $\mathrm{Li}^{+}$ions of macroporoustype MSC-1 resin swollen in water, are independent of temperature. However, relaxation time $\left(T_{2}\right)_{\mathrm{SE}}$ of $\mathrm{Li}^{+}$ions was dependent on temperature, and activation energy 


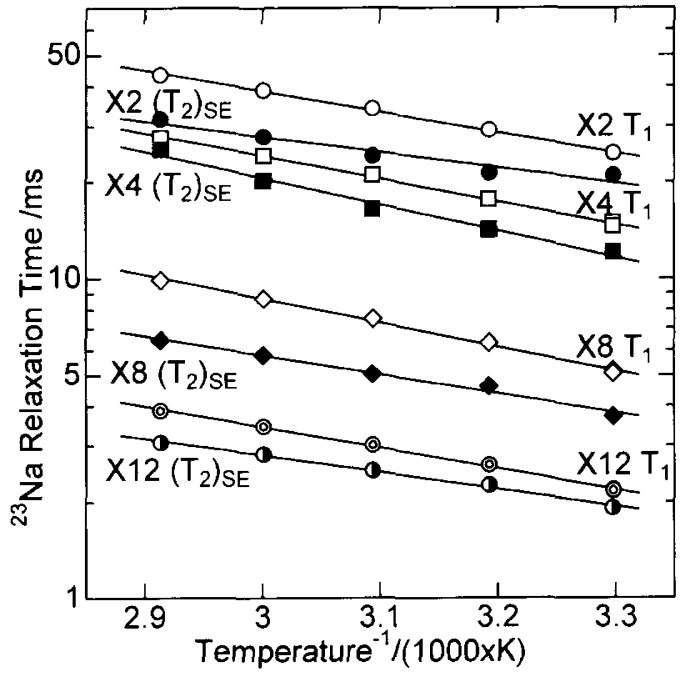

Figure 6. Temperature dependence of ${ }^{23} \mathrm{Na}$ spin-lattice relaxation time $T_{1}$ (opened symbol), and spin-spin relaxation time $\left(T_{2}\right)_{\mathrm{SE}}$ (closed symbol) within gel-type ion-exchange resin $50 \mathrm{~W}-\mathrm{X} 2$, $50 \mathrm{~W}-\mathrm{X} 4,50 \mathrm{~W}-\mathrm{X} 8$, and $50 \mathrm{~W}-\mathrm{X} 12$ in water. Symbol $\bigcirc$ is within $50 \mathrm{~W}-\mathrm{X} 2, \square$ in $50 \mathrm{~W}-\mathrm{X} 4, \diamond$ in $50 \mathrm{~W}-\mathrm{X} 8$, and $\odot$ in $50 \mathrm{~W}-\mathrm{X} 12$. Solid line was fitted using a least-squares method.

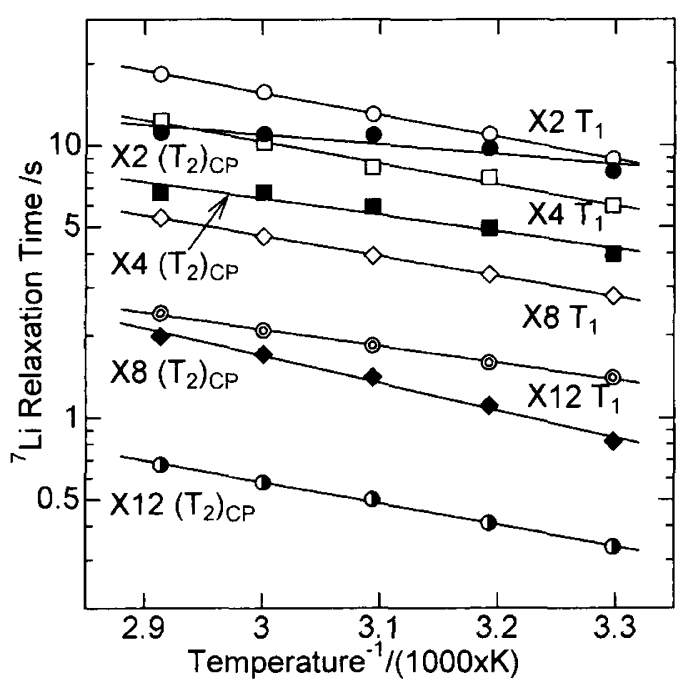

Figure 7. Temperature dependence of ${ }^{7} \mathrm{Li}$ spin-lattice relaxation time $T_{1}$ (opened symbol), and spin-spin relaxation time $\left(T_{2}\right)_{\mathrm{CP}}$ (closed symbol) within gel-type ion-exchange resin 50W-X2, $50 \mathrm{~W}-\mathrm{X} 4,50 \mathrm{~W}-\mathrm{X} 8$, and $50 \mathrm{~W}-\mathrm{X} 12$ in water. Symbol $\bigcirc$ is within $50 \mathrm{~W}-\mathrm{X} 2, \square$ in $50 \mathrm{~W}-\mathrm{X} 4, \diamond$ in $50 \mathrm{~W}-\mathrm{X} 8$, and $\bigcirc$ in $50 \mathrm{~W}-\mathrm{X} 12$. Solid line was fitted using a least-squares method.

was approximately $30 \mathrm{~kJ} \mathrm{~mol}^{-1}$.

Diffusion Coefficient of Water Molecules and Cations within Gel-Type Ion-Exchange Resin

Diffusion time dependency of the apparent diffusion coefficient of water molecules $\left({ }^{23} \mathrm{Na}\right.$-form resin) and $\mathrm{Li}^{+}$ counter-ions within gel-type of crosslinked ion-exchange resin swollen with water by a modified PFG-STE method is shown in Figures 10 and 11. Apparent diffusion coefficients of water molecules and $\mathrm{Li}^{+}$counter-ions within the ion-exchange resin decreased as crosslinkage increased. The apparent diffusion coefficient of water molecules within the ion-exchange resin of $2 \%$ and $4 \%$ crosslinkage is thus almost independent of diffusion

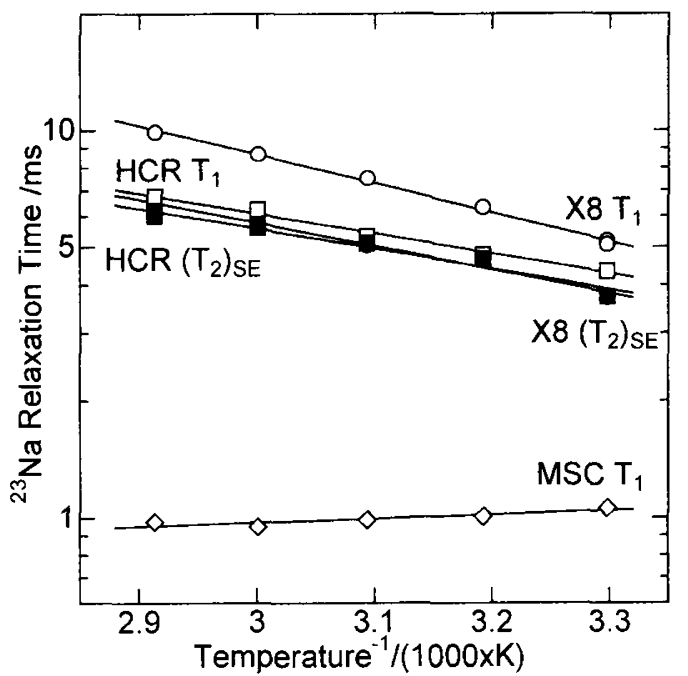

Figure 8. Temperature dependence of ${ }^{23} \mathrm{Na}$ spin-lattice relaxation time $T_{1}$ (opened symbol), and spin-spin relaxation time $\left(T_{2}\right)_{\mathrm{SE}}$ (closed symbol) within gel-type ion-exchange resin $50 \mathrm{~W}-\mathrm{X} 8$ and HCR-W2 in water, and macroporous-type ion-exchange resin MSC-1. Symbol $\bigcirc$ is within 50W-X8, $\square$ is in HCR-W2, and $\diamond$ in MSC-1. Solid line was fitted using a least-squares method.

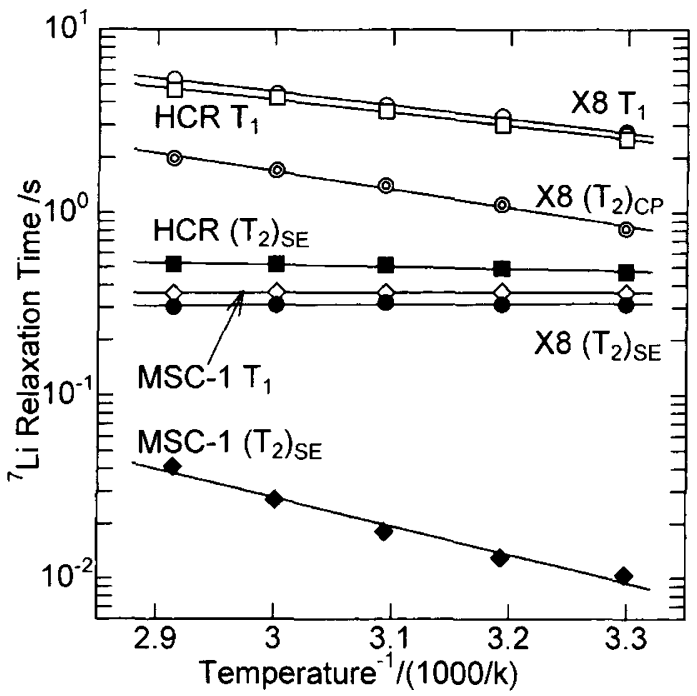

Figure 9. Temperature dependence of ${ }^{7} \mathrm{Li}$ spin-lattice relaxation time $T_{1}$ (opened symbol), and spin-spin relaxation time $T_{2}$ within gel-type ion-exchange resin 50W-X8 and HCR-W2, and macroporous-type ion-exchange resin MSC-1 in water. Symbol $\bigcirc$ is within 50W-X8, $\square$ is in HCR-W2, and $\diamond$ in MSC-1. Closed symbols are $\left(T_{2}\right)_{\mathrm{SE}}$ by Hahn-Echo method and $(0)$ is $\left(T_{2}\right)_{\mathrm{cp}}$ by Carr Purcell Meiboom Gill method. Solid line was fitted using a leastsquares method.

time $t$, as shown in Figure 10. Time-independent diffusion coefficients may be defined as self-diffusion coefficients. However, apparent diffusion coefficients of water molecules within ion-exchange resin of $8 \%$ and $12 \%$ crosslinkage, approach constant values at long diffusion times. As shown in Figure 11, apparent diffusion coefficient of $\mathrm{Li}^{+}$counter-ions within lithium type ionexchange resin at short diffusion time depended on diffusion time, and approached a constant value at long diffusion times. To study the influence of the surface of a particle, comparison was made between $50 \mathrm{~W}-\mathrm{X} 8$ and HCR-W2 resins, having a similar $8 \%$ crosslinkage but 


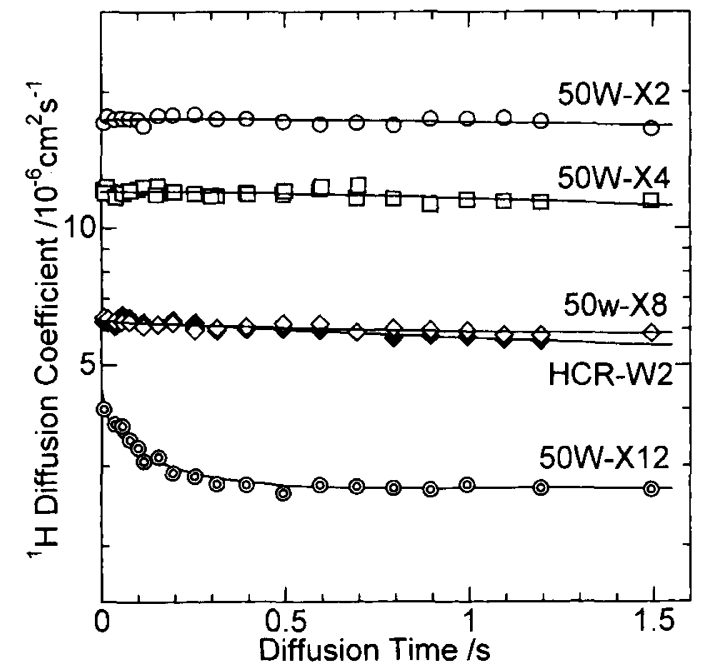

Figure 10. Diffusion time dependence of apparent diffusion coefficient of water molecules within different crosslinkage of $\mathrm{Na}$ formed gel-type ion-exchange resins swollen in water by modified PFG-STE. Symbol $\bigcirc$ is within the ion-exchange resin 50W-X2, $\square$ in 50W-X4, $\diamond$ in 50W-X8, $\mathrm{O}$ in 50W-X12, and $>$ in HCR-W2. Solid lines were fitted using a least-squares method by eq 8 .

different bead size. As they exhibit similar diffusion time dependence in Figures 10 and 11, it may be considered that the apparent diffusion coefficient of the $\mathrm{Li}^{+}$counterions in 50W-X2, 50W-X4, 50W-X8, and 50W-X12 and water molecules in $50 \mathrm{~W}-\mathrm{X} 8$ and $50 \mathrm{~W}-\mathrm{X} 12$ is not influenced by film diffusion at the surface of the resin. Thus apparent diffusion coefficients are restricted by the thin hole wall of the polymer chain within a threedimensional network structure, this being "restricted diffusion". The self-diffusion coefficient was estimated by extrapolation of apparent diffusion coefficients $D$ at diffusion times $t=0$ in Figures 10 and 11. Diffusion coefficient of the water molecules and $\mathrm{Li}^{+}$counter-ions decreased as crosslinkage increased.

Apparent diffusion coefficients of $\mathrm{Li}^{+}$counter-ions within resin swollen in $1 \mathrm{M} \mathrm{LiCl}$ aqueous solution and water molecules in $1 \mathrm{M} \mathrm{NaCl}$ aqueous solution showed similar dependence on diffusion time as within a resin in water.

By the PFG-SE method at time $\Delta 3$ to $25 \mathrm{~ms}$, the diffusion coefficient of $\mathrm{Na}^{+}$counter-ions within $50 \mathrm{~W}-\mathrm{X} 2$ resin swollen with water was $(6.32 \pm 0.63) \times 10^{-6} \mathrm{~cm}^{2} \mathrm{~s}^{-1}$, within 50W-X4 resin was $(3.59 \pm 0.36) \times 10^{-6} \mathrm{~cm}^{2} \mathrm{~s}^{-1}$, and within $50 \mathrm{~W}-\mathrm{X} 8 \mathrm{resin},(1.88 \pm 0.19) \times 10^{-6} \mathrm{~cm}^{2} \mathrm{~s}^{-1}$ as in Table II. Relaxation times, $T_{1}$ and $T_{2}$ of the $\mathrm{Na}^{+}$ions within the ion-exchange resin are very short, and thus it was not possible to observe the diffusion time dependence of apparent diffusion coefficient using PFG-SE NMR method at diffusion times less than several milliseconds.

Apparent diffusion coefficients of $\mathrm{Na}^{+}$and $\mathrm{Li}^{+}$ions, and water molecules within gel-type ion-exchange resins were measured at different temperatures. The values were almost linear against the reciprocal of temperature, and activation energy $\Delta E$ of molecular and ionic motion may be obtained from Arrhenius plots of $\ln \left(D_{0}\right) \propto$ $-(\Delta E / R T)$ as shown in Table II. Activation energy $\Delta E$ of translational motion of water molecules and $\mathrm{Na}^{+}$and

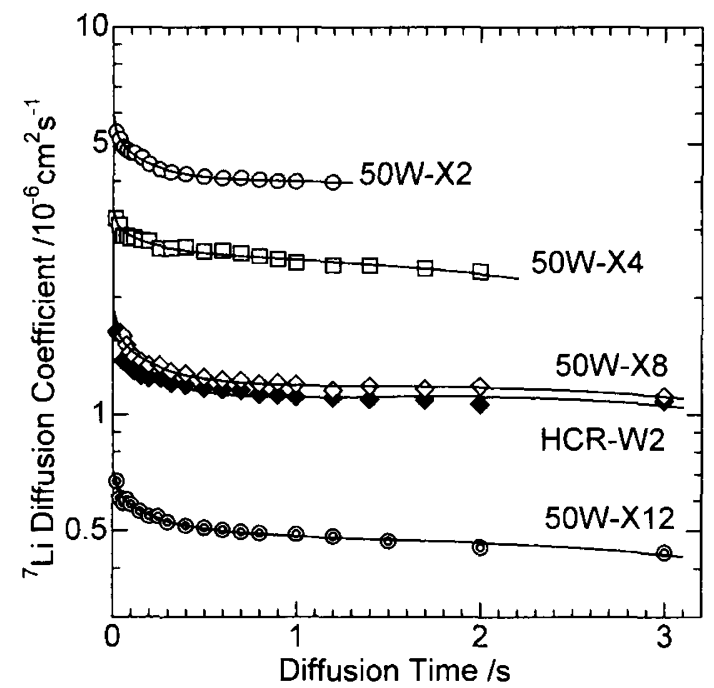

Figure 11. Diffusion time dependence of apparent diffusion coefficient of $\mathrm{Li}^{+}$ions within different crosslinkage of $\mathrm{Li}$-formed geltype ion-exchange resins swollen in water by modified PFG-STE. $O$ is within the ion-exchange resin $50 \mathrm{~W}-\mathrm{X} 2, \square$ in $50 \mathrm{~W}-\mathrm{X} 4, \diamond$ in 50W-X8, in 50W-X12, and in HCR-W2. Solid lines were fitted using a least-squares method by eq 8 .

$\mathrm{Li}^{+}$ions within the resin was almost same as for that motion of ions in the corresponding aqueous solution.

\section{DISCUSSION}

Spin-Lattice Relaxation Time $T_{1}$ and Spin-Spin Relaxation Time $T_{2}$

Influence of Crosslinkage for Spin-Lattice Relaxation Time $T_{1}$. If a nucleus with quantum number greater than $1 / 2, I \neq 1 / 2$ such as ${ }^{23} \mathrm{Na}$ and ${ }^{7} \mathrm{Li}$, is considered, relaxation is generally dominated by nuclear quadrupolar relaxation, and $T_{2}$ is almost equal to $T_{1}$ at extreme narrowing. Relaxation time $\left(T_{1}\right)_{\mathrm{QP}},\left(T_{2}\right)_{\mathrm{QP}}$ of nuclear quadrupole interaction, under the condition $\left(\omega_{0} \tau_{\mathrm{c}}\right)^{2} \ll 1$, is represented by ${ }^{9}$

$$
\begin{aligned}
1 /\left(T_{1}\right)_{\mathrm{QP}}= & 1 /\left(T_{2}\right)_{\mathrm{QP}}=(3(2 I+3)) /\left(I^{2}(2 I-1)\right)\left(1+\eta^{2} / 3\right)\left(\pi^{2} / 10\right) \\
& \left(e^{2} q Q / h\right)^{2} \tau_{\mathrm{c}}
\end{aligned}
$$

where $I$ is the spin quantum number, $\eta$ is quadrupolar asymmetry parameter, $q$ is electric field gradient at the nucleus, and $\tau_{\mathrm{c}}$ is random correlation time of a molecule (ion). The term $\left(\mathrm{e}^{2} q Q / h\right)$ is the quadrupole coupling constant. From eq 4 , relaxation time $\left(T_{1}\right)_{\mathrm{QP}}$ of a nuclear quadrupole interaction is reflected by the rotational motion of the molecule or ion.

Relaxation time, $T_{1}$, for the dissociated $\mathrm{Na}^{+}$and $\mathrm{Li}^{+}$ ions in different ion-exchange resins at $30^{\circ} \mathrm{C}$ is shown in Figure 12. Relaxation time $T_{1} \mathrm{~s}$ of ${ }^{23} \mathrm{Na}$ and ${ }^{7} \mathrm{Li}$ decreased as the degree of crosslinkage of resins increased. Thus higher crosslinkage affects relaxation time. Relative value between observed and extrapolated $T_{1}$ within the ion-exchange resin was calculated to as (relative value) =(observed $\left.T_{1}\right) /\left(\right.$ extrapolated $T_{1}$ to crosslinkage $=0$ ), where (extrapolated $T_{1}$ to crosslinkage $=0$ ) was estimated to $0 \%$ crosslinking in Figure 12 by extrapolation. Relative value of $T_{1}$ in ${ }^{23} \mathrm{Na} \mathrm{NMR}$ was 0.69 in $2 \%$ crosslinkage resin, 0.38 for $4 \%, 0.13$ for $8 \%$ and 0.06 for $2 \%$, respectively. Relative value of $T_{1}$ in ${ }^{7} \mathrm{Li}$ NMR are 
Table II. Self-diffusion coefficient $D_{0}\left(\mathrm{~cm}^{2} \mathrm{~s}^{-1}\right){ }^{a}$ of ${ }^{1} \mathrm{H}$ (Na-formed resin), ${ }^{23} \mathrm{Na}$ and ${ }^{7} \mathrm{Li}$ NMR within different crosslinkage of ion-exchange resin in water at $30^{\circ} \mathrm{C}$, and activation energy $\Delta E\left(\mathrm{~kJ} \mathrm{~mol}^{-1}\right)$ obtained from Arrhenius plots of self-diffusion coefficient $D_{0}$

\begin{tabular}{|c|c|c|c|c|c|c|c|}
\hline & \multirow{2}{*}{ Crosslinkage } & \multicolumn{2}{|c|}{${ }^{23} \mathrm{Na} \mathrm{NMR}$} & \multicolumn{2}{|c|}{${ }^{7} \mathrm{Li}$ NMR } & \multicolumn{2}{|c|}{${ }^{1} \mathrm{H} \mathrm{NMR}^{\mathrm{b}}$} \\
\hline & & $D_{0} \times 10^{6}$ & $\Delta E$ & $D_{0} \times 10^{6}$ & $\Delta E$ & $D_{0} \times 10^{6}$ & $\Delta E$ \\
\hline $50 \mathrm{~W}-\mathrm{X} 2$ & $2 \%$ & $6.32 \pm 0.63$ & $16.1 \pm 1.6$ & $5.92 \pm 0.59$ & $17.9 \pm 1.8$ & $17.3 \pm 1.7$ & $21.3 \pm 2.1$ \\
\hline $50 \mathrm{~W}-\mathrm{X} 4$ & $4 \%$ & $3.59 \pm 0.36$ & $17.1 \pm 1.7$ & $3.34 \pm 0.33$ & $16.6 \pm 1.7$ & $12.0 \pm 1.2$ & $18.9 \pm 1.9$ \\
\hline $50 \mathrm{~W}-\mathrm{X} 8$ & $8 \%$ & $1.88 \pm 0.19$ & $18.3 \pm 1.8$ & $1.82 \pm 0.18$ & $17.7 \pm 1.8$ & $6.38 \pm 0.64$ & $18.9 \pm 1.9$ \\
\hline $50 \mathrm{~W}-\mathrm{X} 12$ & $12 \%$ & & & $0.712 \pm 0.71$ & $21.7 \pm 2.2$ & $4.29 \pm 0.43$ & $22.9 \pm 2.3$ \\
\hline HCR-W2 & $8 \%$ & & & $1.72 \pm 0.17$ & & $6.15 \pm 0.62$ & \\
\hline $1 \mathrm{M} \mathrm{NaCl}^{\mathrm{c}}$ & & $13.5 \pm 1.4$ & $18.4 \pm 1.8$ & & & $23.9 \pm 2.4$ & $19.8 \pm 2.0$ \\
\hline $1 \mathrm{M} \mathrm{LiCl}^{\mathrm{c}}$ & & & & $10.2 \pm 1.0$ & & & \\
\hline
\end{tabular}

$0.69,0.46,0.13$, and 0.11 for $2 \%, 4 \%, 8 \%$, and $12 \%$, respectively. Assuming same quadrupole coupling constants for each nuclei, ${ }^{5}$ and small contribution for relaxation time with concentration of counter-ion within the resin, relative rates are related to rotational motion of dissociated $\mathrm{Na}^{+}$and $\mathrm{Li}^{+}$ions within a resin, from eq 4. Rotational motion of ions within more crosslinked resins is slower than in less crosslinked resins, and ions move 1.6 times within $2 \%$ crosslinkage resin, 2.6 times for $4 \%, 7.7$ times for $8 \%$, and 17.9 times for $12 \%$, slower than in $0 \%$ crosslinked resin. The freedom of motion of $\mathrm{Na}^{+}$and $\mathrm{Li}^{+}$ions thus decreases as crosslinkage increases. Accompanied with increased crosslinkage, it is clear that the three-dimensional network structure becomes small, and is strongly bounded by the ionexchange resin. Relaxation times for ${ }^{23} \mathrm{Na}$ and ${ }^{7} \mathrm{Li} \mathrm{NMR}$ are different at higher crosslinkage because of fixed ions within the ion-exchange resin, selectivity of the resin and internal segmental motion of the three-dimensional structure of the copolymer chain.

Activation energy of rotational motion of $\mathrm{Na}^{+}$counterions within the gel-type ion-exchange resin was within 12 to $14 \mathrm{~kJ} \mathrm{~mol}^{-1}$, and for $\mathrm{Li}^{+}$counter-ions 12 to $16 \mathrm{~kJ} \mathrm{~mol}^{-1}$. Activation energy of motion of the $\mathrm{Na}^{+}$ counter-ion and the $\mathrm{Li}^{+}$counter-ion was larger than for ions in the corresponding aqueous solution. And thus the rotational motion of the counter-ion within the ionexchange resin is strongly influenced. With $\mathrm{Li}^{+}$ions within the ion-exchange resin, that motion of low crosslinkage is influenced more strongly by crosslinkage of ion-exchange resin.

Influence of Chemical Exchange of Spin-Spin Relaxation Time $T_{2}$ for $\mathrm{Li}^{+}$Ions. As shown in Table I, relaxation time $\left(T_{2}\right)_{\mathrm{SE}}$ of ${ }^{7} \mathrm{Li}$ within the resin was quite different to $T_{1}$. The influence of the magnetic field inhomogeneity of the sample and existence of chemical exchange are thus significant. Effect of chemical exchange on the relaxation time $\left(T_{2}\right)_{\mathrm{SE}}$ is quite common, but affects little on relaxation time $T_{1}$. Relaxation time $\left(T_{2}\right)_{\mathrm{SE}}$ by $\mathrm{SE}$ method is given by ${ }^{9,11}$

$$
1 /\left(T_{2}\right)_{\mathrm{SE}}=1 /\left(T_{2}\right)_{\mathrm{QP}}+1 /\left(T_{2}\right)_{\mathrm{EX}}+1 / T_{2}^{*}=\pi v_{1 / 2}
$$

where $v_{1 / 2}$ is the half width of the signal, $\left(T_{2}\right)_{\mathrm{EX}}$ is the spin-spin relaxation time contribution by chemical exchange, and $T_{2}{ }^{*}$, spin-spin relaxation time by all other mechanisms, that is, contribution arising from inhomo-

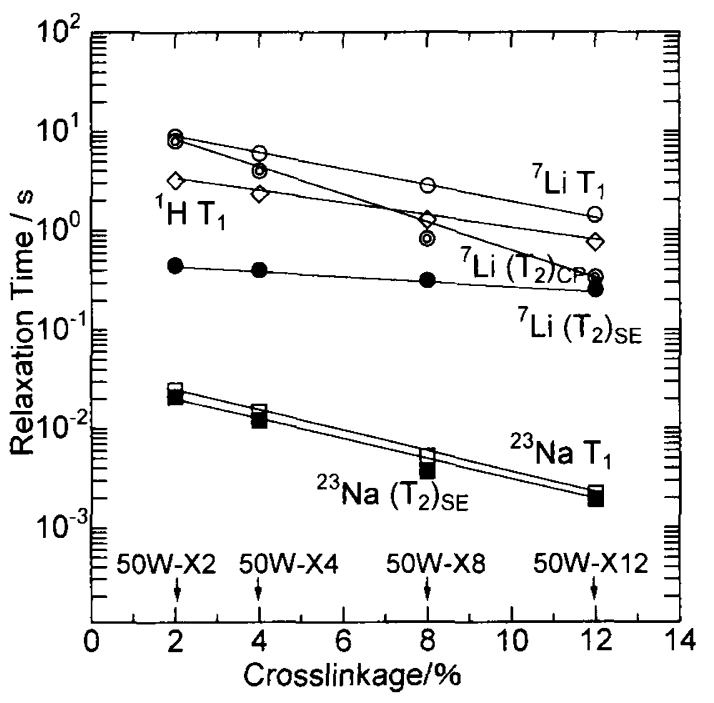

Figure 12. Crosslinkage dependence of spin-lattice relaxation time $T_{1}$ (opened symbol), and spin-spin relaxation time $T_{2}$ (closed symbol) of dissociated $\mathrm{Na}^{+}$and $\mathrm{Li}^{+}$ions and mobile water within gel-type ion-exchange resin in water at $30^{\circ} \mathrm{C}$. Symbol $\bigcirc$ is relaxation time of sodium ions, $\square$ of lithium ions, and $\diamond$ of water(within Na-formed resin). Solid line was fitted using a least-squares method.

geneity of the magnetic field and etc. Relaxation time $\left(T_{2}\right)_{\mathrm{CP}}$ from the CP method and relaxation time $\left(T_{1}\right)_{\rho}$ by the spin locking method are given by ${ }^{19}$

$$
\begin{aligned}
& 1 /\left(T_{2}\right)_{\mathrm{CP}} \doteqdot 1 /\left(T_{1}\right)_{\mathrm{QP}}+P_{\mathrm{a}} P_{\mathrm{b}}(\delta \omega)^{2} \tau_{\mathrm{EX}}\left(1-\tau_{\mathrm{EX}} / \tau_{\mathrm{CP}}\right) \\
& 1 /\left(T_{1}\right)_{\rho} \doteqdot 1 /\left(T_{1}\right)_{\mathrm{QP}}+(\delta \omega)^{2} \tau_{\mathrm{EX}} / 4\left(1+\omega_{1}{ }^{2} \tau_{\mathrm{EX}}{ }^{2}\right)
\end{aligned}
$$

respectively, where $\delta \omega$ is the chemical shift difference between the two sites of chemical exchange. $\tau_{\mathrm{EX}}$ is rate of chemical exchange, $P_{\mathrm{a}}$ and $P_{\mathrm{b}}$ are site populations. Relaxation time $\left(T_{2}\right)_{\mathrm{CP}}$ by the $\mathrm{CP}$ method and relaxation time $\left(T_{1}\right)_{\rho}$ by the spin locking method were used to remove the influence of inhomogeneous magnetic field. For larger bead size HCR-W2 resin with the same crosslinkage as 50W-X8, the relaxation times $T_{1}$ and $T_{2}$ of the $\mathrm{Li}^{+}$ ions within HCR-W2 exhibit similar tendency as 50W-X8. If the influence of the resin surface is ignored, relaxation time $\left(T_{2}\right)_{\mathrm{SE}}$ of ${ }^{7} \mathrm{Li}$ within gel-type resin may be strongly influenced by magnetic field inhomogeneity.

In the case of $50 \mathrm{~W}-\mathrm{X} 2$, at $\tau_{\mathrm{CP}}$ from 1 to $10 \mathrm{~ms}$, relaxa- 
tion time $\left(T_{2}\right)_{\mathrm{CP}}$ of $\mathrm{Li}^{+}$ions by CP method is $T_{1} \geqq\left(T_{2}\right)_{\mathrm{CP}} \gg$ $\left(T_{2}\right)_{\mathrm{SE}}$, within experimental error, and is not dependent on $\tau_{\mathrm{CP}}$. It is clear that the relaxation time of chemical exchange $\left(T_{2}\right)_{\text {EX }}$ makes only a very small contribution to spin-spin relaxation $\left(T_{2}\right)_{\mathrm{CP}}$ by eq 6 . Sites of chemical exchange may be (a), (b), and (c) of $\left\{\mathrm{R}-\mathrm{SO}_{3} \mathrm{Li}(\mathrm{a})\right\}=$ $\left\{\mathrm{R}_{-} \mathrm{SO}_{3}{ }^{-}+\mathrm{Li}^{+}(\mathrm{b})\right.$ inside resin $\}$, or $\left\{\mathrm{Li}^{+}(\mathrm{b})\right.$ inside resin $\}$ $\Longrightarrow\left\{\mathrm{Li}^{+}(\mathrm{c})\right.$ outside resin $\}$. When $\delta \omega$ is chemical shift difference of the two sites as the fixed and dissociated counter-ion, or the dissociated counter-ion and ion in the bulk water, the observed signal is assigned a dissociated site(b), the dissociated counter-ion in the resin. In the case of $50 \mathrm{~W}-\mathrm{X} 8$, relaxation time $\left(T_{2}\right)_{\mathrm{CP}}$ of interval time $\tau_{\mathrm{CP}}$ at 1 to $10 \mathrm{~ms}$ by $\mathrm{CP}$ method, and relaxation time $\left(T_{1}\right)_{\rho}$ with strength $\omega_{1}$ of 100 to $4 \times 10^{3} \mathrm{~s}^{-1}$ by the spin locking method ${ }^{11,19}$ are shown in the order $T_{1}>\left(T_{1}\right)_{\rho}$ $\doteqdot\left(T_{2}\right)_{\mathrm{CP}}>\left(T_{2}\right)_{\mathrm{SE}}$ (at $194 \mathrm{MHz}$ for ${ }^{7} \mathrm{Li}, T_{1}=3.46 \mathrm{~s},\left(T_{1}\right)_{\rho}=$ $0.76 \mathrm{~s},\left(T_{2}\right)_{\mathrm{CP}}=0.75 \mathrm{~s},\left(T_{2}\right)_{\mathrm{SE}}=0.26 \mathrm{~s}$, and at $105 \mathrm{MHz}, T_{1}$ $=2.78 \mathrm{~s},\left(T_{2}\right)_{\mathrm{CP}}=0.82 \mathrm{~s}$, and $\left.\left(T_{2}\right)_{\mathrm{SE}}=0.31 \mathrm{~s}\right)$, and $\left(T_{2}\right)_{\mathrm{CP}}$ and $\left(T_{1}\right)_{\rho}$ are not dependent on $\tau_{\mathrm{CP}}$ or $\omega_{1}$ under the experimental conditions. From estimated $\tau_{\mathrm{EX}} \gg 10^{-2} \mathrm{~s}$ by eq 7 at $\omega_{1}{ }^{2} \tau_{\mathrm{EX}}{ }^{2} \gg 1$, it is obvious that the relaxation time due to chemical exchange $\left(T_{2}\right)_{\mathrm{EX}}$ contributes to $\left(T_{2}\right)_{\mathrm{CP}}$ in the ion-exchange system within gel-type ion-exchange resin.

Relaxation Time of Counter-Ion within MacroporousType Ion-Exchange Resin. With macroporous-type resin, MSC-1, signals of ${ }^{1} \mathrm{H}$ NMR, ${ }^{23} \mathrm{Na} \mathrm{NMR}$ in $\mathrm{NaCl}$ aqueous solution and ${ }^{7} \mathrm{Li} \mathrm{NMR}$ in $\mathrm{LiCl}$ aqueous solution appear as only one peak. The rate of chemical exchange is thus faster than the reciprocal of the chemical shift difference $\delta \omega$ between water molecules or ions inside and outside the resin. Relaxation time $\left(T_{1}\right)_{\rho}$ of ${ }^{7} \mathrm{Li}$ NMR does not depend on $\omega_{1}$ with strength of locking field $\omega_{1}$ from 100 to $4 \times 10^{3} \mathrm{~s}^{-1}$, and is obtained with $T_{1} \gg\left(T_{1}\right)_{\rho} \doteqdot\left(T_{2}\right)_{\mathrm{SE}} \doteqdot 0.01$ s. As $\left(T_{1}\right)_{\rho}$ of ${ }^{7} \mathrm{Li}$ NMR observed under the strongest locking power is measured under the condition of $\omega_{1}^{2} \tau_{\mathrm{EX}}{ }^{2} \ll$ $1,\left(T_{2}\right)_{\mathrm{SE}}$ of ${ }^{7} \mathrm{Li}$ NMR is estimated to be approximately equal to $\left(T_{2}\right)_{\mathrm{EX}}$ of ${ }^{7} \mathrm{Li} \mathrm{NMR}$ from eq 5 . That is, $\left(T_{2}\right)_{\mathrm{SE}}$ of gel type HCR-W2 resin with the same crosslinkage and bead size is much longer than $\left(T_{2}\right)_{\mathrm{SE}}$ of macroporous-type resin MSC-1. $\left(T_{2}\right)_{\mathrm{SE}}$ of ions with MSC-1 is thus dominated by chemical exchange, and the rate of exchange is smaller than $10^{-4} \mathrm{~s}, \tau_{\mathrm{EX}} \ll 10^{-4} \mathrm{~s}$ by eq 7 . In Figures 8 and 9 , relaxation time $T_{1}$ of $\mathrm{Na}^{+}$and $\mathrm{Li}^{+}$ions of macroporoustype MSC-1 resin swollen in water, is not dependent on temperature. Relaxation time $\left(T_{2}\right)_{\mathrm{SE}}$ of the $\mathrm{Li}^{+}$ion is dependent on temperature, and the activation energy of chemical exchange was approximately $30 \mathrm{~kJ} \mathrm{~mol}^{-1}$.

\section{Dependence of Apparent Diffusion Coefficient on Diffu- sion Time}

Diffusion Time Dependence of Apparent Diffusion. For the diffusion of ions or molecules, in the absence of a barrier, ions or molecules are allowed free diffusion in all directions in aqueous solution. For water molecules and counter-ions within the ion-exchange resin, the network structure of the resin itself restricts diffusion. ${ }^{4,6}$ For diffusion distance, $R$ of a molecule whose diffusion coefficient is to be measured, as in the case of free diffusion, $R=(2 D t)^{1 / 2}$, the motion of a molecule relies on size $r$ of the compartment within the boundary permeability. If $R$ is small in comparison with $r$, the motion of a mole- cule shows similar diffusion coefficient as a free molecule uninfluenced by collision with the boundary wall. Apparent diffusion coefficients obtained with the PFGNMR method agree well with actual diffusion coefficients. $^{6,20}$ If $R$ of the molecule is larger in comparison with $r$, maximum diffusion distance becomes shorter as the molecule is constrained by the size of the compartment and apparent diffusion coefficient becomes smaller than the actual diffusion coefficient. Depending on the boundary permeability, the apparent diffusion coefficient strongly relies on the size of the compartment, and thus apparent diffusion coefficient depends on detected diffusion time $t$, the time that defines the diffusion coefficient.

PFG-NMR shows that the diffusion coefficients of water and the $\mathrm{Li}^{+}$ion within the ion-exchange resin are dependent on the diffusion time, and thus these molecules and ions are diffusion restricted because of collisions with cell walls of the ion-exchange resin. The short-time diffusion coefficient is independent of the microscopic details of restricting geometry and depends only on surface-to-volume ratio $\mathrm{S} / \mathrm{V}$ of the pore space. Let us define the time-dependent diffusion coefficient $D(t)$ as $\left\langle r^{2}(t) /(6 t)\right\rangle$, where $\left\langle r^{2}(t)\right\rangle$ is mean-square displacement of spins in time $t$. Under surface relaxation, mean-square displacement is calculated only for spins that survive at time $t$. P. P. Mitra et al. ${ }^{21,22}$ showed that for porous media with smooth boundaries, the apparent diffusion coefficient $D(t)$ is given at short times by

$$
D(t) / D_{0}=1-(4 / 9)(S / V)\left(D_{0} t / \pi\right)^{1 / 2}-\left\{(\mathrm{S} / 12 V)\left(1 / R_{1}+1 / R_{2}\right)-\right.
$$$$
(1 / 6)(\rho S / V)\} D_{0} t+\mathrm{O}\left\{\left(d_{0} t\right)^{3 / 2}\right\}
$$

where $D_{0}$ is the self-diffusion coefficient at $t=0, S$ and $V$ are the pore surface area and pore volume, $R_{1}$ and $R_{2}$ are principal radii of curvature of pore walls, $\rho$ is surface relaxivity, and $\mathrm{O}\left\{\left(d_{0} t\right)^{3 / 2}\right\}$ is a high order term. By applying this to molecules and counter-ions, the self-diffusion coefficient $D_{0}$ of water molecules within the Na-formed gelheteroporous ion-exchange resin structure at $30^{\circ} \mathrm{C}$ is obtained fitting by eq 8 . And self-diffusion coefficient, $D_{0}$ of water molecules of the Na-formed resins in water becomes $(17.3 \pm 1.7) \times 10^{-6} \mathrm{~cm}^{2} \mathrm{~s}^{-1}$ in $50 \mathrm{~W}-\mathrm{X} 2$ with $2 \%$ crosslinkage, $(12.0 \pm 1.2) \times 10^{-6} \mathrm{~cm}^{2} \mathrm{~s}^{-1}$ in $50 \mathrm{~W}-\mathrm{X} 4$ with $4 \%,(6.38 \pm 0.64) \times 10^{-6} \mathrm{~cm}^{2} \mathrm{~s}^{-1}$ in $50 \mathrm{~W}-\mathrm{X} 8$ with $8 \%$ and $(4.29 \pm 0.43) \times 10^{-6} \mathrm{~cm}^{2} \mathrm{~s}^{-1}$ in $50 \mathrm{~W}-\mathrm{X} 12$ with $12 \%$ are shown in Table II. The values become smaller as crosslinkage increases. Self-diffusion coefficients, $D_{0}$ of $\mathrm{Li}^{+}$counter-ion in water at $30^{\circ} \mathrm{C}$ are obtained from eq 8 as $(5.92 \pm 0.59) \times 10^{-6} \mathrm{~cm}^{2} \mathrm{~s}^{-1}$ for $50 \mathrm{~W}-\mathrm{X} 2,(3.34 \pm 0.33)$ $\times 10^{-6} \mathrm{~cm}^{2} \mathrm{~s}^{-1}$ for $50 \mathrm{~W}-\mathrm{X} 4,(1.82 \pm 0.18) \times 10^{-6} \mathrm{~cm}^{2} \mathrm{~s}^{-1}$ for $50 \mathrm{~W}-\mathrm{X} 8$ and $(7.12 \pm 0.71) \times 10^{-7} \mathrm{~cm}^{2} \mathrm{~s}^{-1}$ for $50 \mathrm{~W}-\mathrm{X} 12$ shown in Table II.

Influence of Crosslinkage on Diffusion Coefficient. The diffusion of sodium and lithium ions and water molecules in relation to crosslinkage is the same as for relaxation. These species diffused more slowly in highly crosslinked resins as in Table II. The apparent diffusion coefficient of $\mathrm{Li}^{+}$ions and water molecules was dependent on diffusion time, possibly due to restricted diffusion in the three dimensional network structure of the gelheteroporous ion-exchange resin. 
The self-diffusion coefficient $D_{0}$ of water molecules and $\mathrm{Na}^{+}$and $\mathrm{Li}^{+}$ions within ion-exchange resin decreases almost linearly with higher crosslinkage as in Figure 13. Water molecules and counter-ions within an ionexchange resin swollen in water thus collide with the polymer chain of the three-dimensional network structure of the ion-exchange resin. Average hole size of geltype ion-exchange resin is about $4 \mathrm{~nm}$ reported by $\mathrm{H}$. Shimizu, ${ }^{23}$ and the self-diffusion coefficient $D_{0}$ of the water molecule within the ion-exchange resin is smaller than the unrestricted self-diffusion coefficient. Selfdiffusion coefficient $D_{0}$ is called the apparent diffusion coefficient restricted within a hole. The freedom of translational motion of the water molecule decreases with increase of crosslinkage.

Self-diffusion coefficient $D_{0}$ of $\mathrm{Li}^{+}$ions within the ionexchange resin swollen in water is smaller with higher crosslinkage, as with water molecules. Self-diffusion coefficient $D_{0}$ of $\mathrm{Li}^{+}$ions within the ion-exchange resin decreases by interaction with fixed ions, and hydration effect, as crosslinkage increases. However, as relaxation time of ${ }^{23} \mathrm{Na} \mathrm{NMR}$ is short, the apparent diffusion coefficient dependence on diffusion time was not clarified.

Differences in chemical shift of NMR signal, relaxation time, and diffusion coefficient of the water molecule and counter-ion are caused by the following;

water content of the resin reduced with increasing crosslinkage,

size of holes within the structure of the polymer, strength of interaction with fixed functional groups, hydration effect of ions, and etc.

\section{CONCLUSION}

The dynamics of counter-ions (lithium and sodium ions) and water molecules within several cationexchange resins of crosslinked poly(styrene sulfonic acid) copolymer swollen in water were investigated by NMR spectroscopy.

a. The motion of $\mathrm{Na}^{+}$and $\mathrm{Li}^{+}$counter-ions within the ion-exchange resin swollen in water, was studied on an NMR time scale. The ions relaxed faster within the resin than in aqueous solution, and with higher crosslinking, in gel-type resins. Motion of $\mathrm{Na}^{+}$and $\mathrm{Li}^{+}$ions is restricted more strongly with increase of crosslinkage.

b. Activation energy of rotational motion of $\mathrm{Na}^{+}$ counter-ions within the ion-exchange resin by an Arrhenius plot of relaxation times was from 12 to $14 \mathrm{~kJ} \mathrm{~mol}^{-1}$, and for $\mathrm{Li}^{+}$counter-ions 12 to $16 \mathrm{~kJ} \mathrm{~mol}^{-1}$. And that activation energy of $\mathrm{Na}^{+}$and $\mathrm{Li}^{+}$counter-ions was larger than for ions in the corresponding aqueous solution, and thus rotational motion of counter-ions within the ion-exchange resin is strongly influenced. For $\mathrm{Li}^{+}$ions within the ion-exchange resin, that motion of low crosslinkage is influenced more strongly by crosslinkage of ion-exchange resin. For $\mathrm{Na}^{+}$, that motion is influenced more strongly by degree of crosslinkage.

c. Diffusion coefficients of counter-ion within the ionexchanger may be measured indirectly using chemical or isotopic profiles of breakthrough curve and/or a tracer using isotope and radioisotope as probe, taking several hours. By these methods, it is impossible to separate

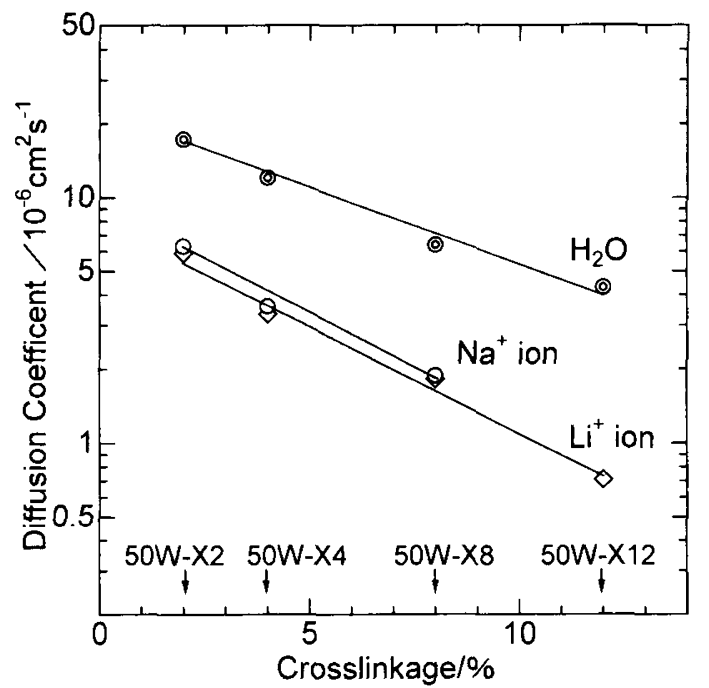

Figure 13. Crosslinkage dependence of self-diffusion coefficients $D_{0}$ of dissociated $\mathrm{Na}^{+}$and $\mathrm{Li}^{+}$ions and mobile water within geltype ion-exchange resin in water at $30^{\circ} \mathrm{C}$. Symbol $\bigcirc$ is selfdiffusion coefficient of sodium ions, $\square$ of lithium ions, and (9) of water(within Na-formed resin). Solid line was fitted using a leastsquares method.

particle diffusion within a resin and film diffusion, and therefore it is difficult to understand the transportation of $\mathrm{Na}^{+}$and $\mathrm{Li}^{+}$ions. The diffusion coefficient of mobile water molecules within ion-exchange resin was directly measured with pulsed field-gradient nuclear magnetic resonance (PFG-NMR) spectroscopy, taking less than one hour. The diffusion coefficients of $\mathrm{Na}^{+}$and $\mathrm{Li}^{+}$ions and water molecules in the gel-type resin may be measured directly by ${ }^{7} \mathrm{Li},{ }^{23} \mathrm{Na}$, and ${ }^{1} \mathrm{H}$ NMR using pulsed field-gradient methods. The species diffused slower in highly crosslinked resin, and more slowly within a resin than aqueous solution. Apparent diffusion coefficients of $\mathrm{Li}^{+}$ion and water molecules were dependent on diffusion time, due to restricted diffusion within the threedimensional network structure of gel-heteroporous types of ion-exchange resins. Restricted diffusion thus depends on three-dimensional network structure. The influence of crosslinkage for diffusion water and $\mathrm{Na}^{+}$and $\mathrm{Li}^{+}$ions within an ion-exchange resin was studied. Because of short relaxation time, the apparent diffusion coefficient of the $\mathrm{Na}^{+}$ions was not dependent on diffusion time.

Acknowledgments. The authors acknowledge the help of Prof. Haruo Seto of University of Tokyo for making diffusion coefficient measurement.

\section{REFERENCES}

1. F. Helfferich, "Ion-exchange," McGraw Hill, New York, N.Y., 1962.

2. a) H. L. Yeager and B. Kipling, J. Phys. Chem., 83, 1836 (1979); b) T. Kataoka, H. Yoshida, and H. Sanada, J. Chem. Eng. Jpn., 7, 105 (1974).

3. a) T. A. Zawodzinski Jr., M. Neemann, L. O. Sillerud, and S. Gottesfeld, J. Phys. Chem., 95, 6040 (1991); b) R. C. T. Slande, J. Barker, and J. H. Strange, Solid State Ionics, 35, 11 (1989).

4. P. T. Callaghan, "Principles of Nuclear Magnetic Resonance Microscopy," Clarendon Press, Oxford, 1991.

5. a) M. Ohuchi, H. Horiuchi, and Y. Sakai, Japanese J. Pol. Sc. Tech., 53, 322, (1996); b) M. Ohuchi, H. Horiuchi, and Y. Sakai, 
Japanese J. Pol. Sc. Tech., 52, 512 (1995)

6. J. E. Tanner, $\mathrm{Ph}$. D. dissertation, University of Wisconsin, 1996.

7. R. M. Cotts, M. J. Hoch, T. Sun, and J. T. Marker, J. Magn. Reson., 83, 252 (1989).

8. G. E. Boyd and B. A. Soldano, J. Amer. Chem. Soc., 75, 6001 (1954).

9. a) T. C. Farrar and E. D. Becker "Pulse and Fourier Transform NMR," Academic Press, New York, N.Y., 1971; b) A. Abragam, "The Principles of Nuclear Magnetism," Oxford University Press, London, 1978; c) A. Carrinton and A. D. McLchlan, "Introduction to Magnetic Resonance," Harper, New York, N. Y., 1967.

10. D. C. Look and I. J. Lowe, J. Chem. Phys., 44, 2995 (1966)

11. M. Ohuchi, T. Fujito, and M. Imanari, J. Magn. Reson., $\mathbf{3 5}$, 415 (1975)

12. M. Busch and E. V. Goldammer, J. Solution Chem., 11, 777 (1982).
13. E. O. Stejskal and J. E. Tanner, J. Chem. Phys., 42, 288 (1965).

14. J. E. Tanner, J. Chem. Phys., 52, 2523 (1970).

15. J. M. Fauth, A. Schweiger, L. Braunschweiler, J. Forrer, and R. R. Ernst, J. Magn. Reson., 66, 74 (1986).

16. K. Tanaka, J. Chem. Soc. Faraday I, 71, 1127 (1975).

17. R. Mills J. Am. Chem. Soc., 77, 6116 (1955).

18. J. Mattiollo, P. J. Basser, and D. LeBihan, J. Magn. Reson. Series, A108, 131 (1994)

19. L. M. Jackman and F. A. Cotton, "Dynamic Nuclear Magnetic Resonance Spectroscopy”, Chapter 4, 5, Academic Press, New York, N. Y., 1975.

20. J. E. Tanner and E. O. Stejskal, J. Chem. Phys., 49, 1768 (1968).

21. P. P. Mitra, P. N. Sen, L. M. Schwartz, and P. LeDoussal, Phys. Rev. Lett., 68, 3555 (1992).

22. P. P. Mitra, L. L. Lautour, R. L. Kleinberg, and L. H. Sotak, J. Magn. Reson., A114, 47 (1995).

23. H. Shimizu, Organo Hi-lites, 50, 65 (1968). 